\title{
Rhetorical Resources for \\ Teaching Responsible \\ Communication of \\ Science
}

J ean Goodwin

Michael Dahlstrom

Mari Kemis

Clark Wolf

Christine Hutchison

Iowa State University

Ames, IA USA

Poroi 10,1 (January 2014)

Keywords: rhetoric of science, science communication, science communication education, science communication ethics, science-policy interface

\section{Responsible Communication of Science}

Teaching has traditionally been one of the offices of rhetoric. Although the genres of interest have varied, rhetoricians over the ages have managed to find steady work in helping young people become adept at the communication tasks their culture values. Indeed, much of what today passes as classical rhetorical theory was originally lore in textbooks, or at best teachers' manuals.

Contemporary rhetorical scholars likewise encounter many opportunities to do the important work of supporting scientists, engineers and other experts as they learn how to share their knowledge with non-expert audiences. The national demand for such instruction is evident in the rise of programs like Stony Brook's Alan Alda Center for Communicating Science (Grushkin, 2010), the American Association for the Advancement of Science's Communicating Science program (AAAS, 2013), and NSF's Science: Becoming the Messenger workshops. More locally, we expect that 
other members of ARST receive the same requests we do to participate in training workshops directed to STEM grad students, faculty, and science communication professionals.

The goal of the Teaching Responsible Communication of Science project (TRCS) at Iowa State University is to enrich such training programs with a rhetorical perspective. In particular, we are developing case-based pedagogical materials that explore the normative dimensions of science communication, encouraging scientists to reflect on the roles (officia) they can productively play in civic deliberations. Through these cases, we want to help scientists to move from asking how to communicate, to asking why. We want to add to training in rhetorical skills, the cultivation of rhetorical judgment. In sum, we aim leverage the current interest in effective communication by adding a dimension of responsible, appropriate, ethical communication as well.

At the same time, our work in the TRCS project contributes a rhetorical perspective to the growing body of research on science communication. This interdisciplinary topic is being explored by colleagues in fields such as risk communication, crisis communication, health communication, and environmental communication, as well as by scholars from practitioner communities such as science journalists and public information officers. Due to the largely social scientific orientation of these scholars, however, the ethical dimension of communication has gone largely unexplored. As a recent survey of the literature concluded, even as "science communication has been made the object of increasing political and academic attention," the topic "has gone almost unnoticed as an area of serious, ethical concern" (Meyer \& Sandøe, 2012). But normativity is what rhetoricians do best. The humanistic perspective provided by rhetorical inquiry can address the ethics gap. By investigating cases in which scientists have met and managed significant communication challenges, we aim to develop a more robust theory of scientists' communicative obligations in the public sphere.

Overall, we see the pedagogical and theory-building goals of the TRCS project as complementary. The deeper understandings of science communication ethics we develop through case-based research serve to enrich the case-based pedagogy. The pedagogy, in turn, keeps the rhetorical theory answerable to the communicators who can use it.

In terms of specifics, the TRCS project team is led by a rhetorician and includes a science communication scholar in the AEJ MC tradition, a philosopher, an educational assessment 
specialist, and a research assistant from the sciences. We collaborate with a science advisory board and a team of fifteen instructors from science and communication disciplines who are testing our materials in universities across the nation. Given the lack of any overarching theory of science communication ethics, we are building from the ground up. We interview scientists across a range of policy-relevant fields, asking them to identify cases in which they themselves or their colleagues met significant challenges when communicating with the public. With help from our advisory board, we identify the most promising cases for further investigation and then interview participants in it representing a variety of perspectives. We will be developing nine case studies over the three years of the grant; three are currently in draft, and can give a sense of what we are aiming at.

The Midwest Climate Statement explores issues raised in the drafting of a public statement that used the severe drought of 2012 as a "teachable moment" to bring issues of climate change adaptation and mitigation before the citizens of an affected state. Questions raised by this case include: Who has scientific authority to speak on the issues? What is the purpose of the communication? Should uncertainties, limitations, and disclaimers be mentioned? What if any sorts of action is it appropriate for scientists to call for? When does scientific advice cross over into advocacy?

Monarchs in the Corn focuses on J ohn Losey's decision to publish a controversial article reporting his preliminary results that indicated that monarch butterfly larvae were harmed when they consumed milkweed dusted with transgenic corn pollen. Questions raised by this case include: Is it appropriate for scientists to take possible public response into account when deciding how to present research findings in print? What features of a scientific article are relevant to the decision about whether or not it is ready for publication?

Science Headlines looks at how the conflicting interests of scientists and public information officers play out in selecting a headline for a press release of a controversial study of environmental-scale effects of GMO crops. Questions raised by this case include: How do the responsibilities in communicating science through academic journals differ from communicating through press releases? How should politically sensitive science be communicated to a general audience? When, if ever, can researchers appropriately be held responsible for the social impacts that result from their public communication with the media? 
One outcome of our initial interviews with scientists is a preliminary survey of the sorts of ethical issues in communicating science of which scientists are aware. In addition to already welldocumented concerns about the legitimacy of advocacy by scientists (Goodwin, 2012), we are finding recognition of problems in managing authority (e.g., what to say when you don't know), in dealing with those who dismiss sound science (i.e., manufactured controversy, Ceccarelli, 2011) and in the difference between "hyping" and legitimately publicizing results.

Interviews focused on specific cases should in addition allow us to give fine-grained accounts of the ethical challenges of communicating complex science in an equally complex political environment. In the Midwest Climate Statement case, for example, we may be able to trace how the scientist-drafters of the statement fell into three different groups, each with its own definition of the rhetorical situation - audience, exigence, and constraints. Because it integrated the goals of these diverse perspectives, the text that emerged from their negotiations was resilient against a range of skeptical challenges.

Overall, the tradition rhetoricians inherit positions us to observe some of what can go wrong in scientists' rhetorical practices. We are also well positioned to observe the limitations of the relentlessly practical orientation of contemporary communication training for scientists. In the Teaching Responsible Communication of Science project, we look forward to using the rhetoricians' position as a fulcrum for shifting, slightly, both the scholarly conversation about and communication pedagogy for science communication. We hope to accomplish what Leah Ceccarelli (2013) has called "the shift from understanding to action" by taking our well-honed "ability to discern" and implementing it through our traditional, albeit modest, office: teaching.

Copyright (C) 2014 J ean Goodwin, Michael Dahlstrom, Mari Kemis, Clark Wolf, Christine Huthcison.

\section{ACKNOWLEDGEMENTS}

This material is based upon work supported by the National Science Foundation under Grant Number 1237495. Any opinions, findings, and conclusions or recommendations expressed in this material are those of the authors and do not necessarily reflect the views of the National Science Foundation. 


\section{REFERENCES}

American Association for the Advancement of Science. (2013). Communicating science: Tools for scientists and engineers. Retrieved from http:/ / www.aaas.org/ communicatingscience

Ceccarelli, L. (2011). Manufactured scientific controversy: Science, rhetoric, and public debate. Rhetoric and Public Affairs, 14(2), 195-228.

Ceccarelli, L. (2013). To whom do we speak? The audiences for scholarship on the rhetoric of science and technology. Poroi 9(1). Retrieved from http:// ir.uiowa.edu/ cgi/ viewcontent.cgi?article=1151\&context $=$ poroi

Goodwin, J . (2012). What is "responsible advocacy" in science? Good advice. In J . Goodwin (Ed.), Between scientists \& citizens: Proceedings of a conference at Iowa State University, J une 1-2, 2012 (pp. 151- 161). GPSSA. Retrieved from

https:// dl.dropboxusercontent.com/ u/ 1809847/ goodwin/Go odwin2012.pdf

Grushkin, D. (2010). Try acting like a scientist: Actor Alan Alda teaches a new generation of researchers how to communicate with the public. The Scientist. Retrieved from http://www.thescientist.com/?articles.view/articleNo/29190/title/Tryacting-like-a-scientist/

Meyer, G., \& Sandøe, P. (2012). Going public: Good scientific conduct. Science and Engineering Ethics, 18(2), 173- 197. 